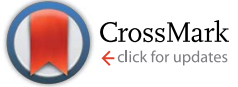

Cite this: RSC Adv., 2015, 5, 73670

Received 9th June 2015

Accepted 21st August 2015

DOI: 10.1039/c5ra10982e

www.rsc.org/advances

\section{Non-aqueous template-assisted synthesis of mesoporous nanocrystalline silicon orthophosphate $\uparrow$}

\author{
Ales Styskalik, ${ }^{\text {ab }}$ David Skoda, ${ }^{\text {ab }}$ Zdenek Moravec, $^{\text {a }}$ Pavla Roupcova, ${ }^{c}$ Craig E. Barnes ${ }^{d}$ \\ and Jiri Pinkas*ab
}

The first synthesis of mesoporous nanocrystalline silicon orthophosphate $\mathrm{Si}_{5} \mathrm{P}_{6} \mathrm{O}_{25}$ is presented. The synthetic procedure is based on the non-hydrolytic sol-gel reaction in the presence of Pluronic P123 template and subsequent calcination in air. The condensation of silicon acetate, Si(OAc) 4 , and tris(trimethylsilyl) phosphate, $\mathrm{OP}\left(\mathrm{OSiMe}_{3}\right)_{3}$ (TTP), in non-aqueous solvents driven by elimination of trimethylsilyl acetate provides a homogeneous network with a high content of $\mathrm{Si}-\mathrm{O}-\mathrm{P}$ bonds and $\mathrm{SiO}_{6}$ moieties. After burning out the template, mesoporous silicon orthophosphate was obtained with surface areas up to $128 \mathrm{~m}^{2} \mathrm{~g}^{-1}$ and pore sizes around $20 \mathrm{~nm}$. The nanocrystalline $\mathrm{Si}_{5} \mathrm{P}_{6} \mathrm{O}_{25}$ phase forms relatively easily $\left(500{ }^{\circ} \mathrm{C}, 4 \mathrm{~h}\right)$ in comparison with other synthetic routes. All samples were characterized by SEM, TEM, elemental analysis, TGA, nitrogen adsorption, SAXS, ${ }^{1} \mathrm{H},{ }^{13} \mathrm{C},{ }^{29} \mathrm{Si}$, and ${ }^{31} \mathrm{P}$ solid-state NMR spectroscopy, and powder XRD. These xerogels showed superior catalytic activity and selectivity in methylstyrene dimerization.

\section{Introduction}

Silicophosphate compounds are widely used as advanced technology materials. One of their key features is stable Brønsted acidity at elevated temperatures which makes them suitable for applications in fuel cells as proton conducting electrolytes $^{\mathbf{1 , 2}}$ and in heterogeneous catalysis. ${ }^{3-6}$

The active centers in the solid phosphoric acid catalyst (SPA) are acidic $\mathrm{P}-\mathrm{OH}$ groups. These arise from various (silico)phosphoric acids (ortho, pyro, poly) which are occluded in the pores or attached at the surface of support phases, such as crystalline silicon phosphates. ${ }^{5}$ SPA catalysts are considered acidic without any redox effects and propene oligomerization is often used as a test reaction in industrial applications. Many reaction parameters influence catalytic activity and specificity, one of them being the content of water in feedstock. Water slowly hydrolyzes crystalline silicon phosphates (support of the catalyst) and restores $\mathrm{P}-\mathrm{OH}$ groups on the surface. ${ }^{4}$ Active phosphate species are continuously washed out in the form of phosphoric acids and catalysts without this type of refreshing (e.g. silica gel impregnated with $\mathrm{H}_{3} \mathrm{PO}_{4}$ ) show short lifetimes. ${ }^{4}$

\footnotetext{
${ }^{a}$ Masaryk University, Department of Chemistry, Kotlarska 2, CZ-61137 Brno, Czech Republic.E-mail:jpinkas@chemi.muni.cz; Fax: +420549492443; Tel: +420549496493 ${ }^{b}$ CEITEC MU, Masaryk University, Kamenice 5, CZ-62500 Brno, Czech Republic ${ }^{c}$ CEITEC BUT, Brno University of Technology, Technicka 10, 616 oo Brno, Czech Republic

${ }^{d}$ University of Tennessee, Department of Chemistry, Knoxville, TN 37996-1600, USA † Electronic supplementary information (ESI) available. See DOI: 10.1039/c5ra10982e
}

The synthesis of silicophosphate compounds and SPA catalysts can be accomplished by high temperature reactions, ${ }^{7-9}$ chemical vapor deposition, ${ }^{10}$ or by hydrolytic ${ }^{2,11-13}$ and nonhydrolytic sol-gel techniques. However, reproducibility can be problematic for the high temperature synthesis from silica and $\mathrm{P}_{4} \mathrm{O}_{10}, \mathrm{H}_{3} \mathrm{PO}_{4}$, or ammonium phosphates as these reactions produce many different crystalline compounds, such as silicon pyrophosphate, $\mathrm{SiP}_{2} \mathrm{O}_{7}$ (in eight structural polymorphs) and silicon orthophosphate, $\mathrm{Si}_{5} \mathrm{O}\left(\mathrm{PO}_{4}\right)_{6} \cdot{ }^{\mathbf{8 , 9 , 1 4 - 1 6}} \mathrm{Si}-\mathrm{O}-\mathrm{P}$ bonds are only formed by the condensation of $\mathrm{Si}-\mathrm{OH}$ and $\mathrm{P}-\mathrm{OH}$ on heating these $\mathrm{SiO}_{2}-\mathrm{H}_{3} \mathrm{PO}_{4}$ heterogeneous mixtures and crystallization to various silicophosphate phases ensues above about $150{ }^{\circ}$ C. $^{17-19}$ Similar to high temperature syntheses, the hydrolytic sol-gel method is not easily controlled. Silicophosphate xerogels prepared from hydrolyzed TEOS and $\mathrm{H}_{3} \mathrm{PO}_{4}$ with a 1P : 2Si molar ratio display a signal for isolated orthophosphate in the ${ }^{31} \mathrm{P}$ MAS NMR spectra of heat treated samples even up to $600{ }^{\circ} \mathrm{C}$ where it coexists with crystalline silicophosphate phases containing octahedral $\mathrm{SiO}_{6}$ units. ${ }^{20}$

Previously, we have shown than non-hydrolytic sol-gel reactions based on ester elimination allow the preparation of amorphous, microporous silicophosphate xerogels with high homogeneity on atomic level. ${ }^{21}$ The crystallization of silicon orthophosphate from these xerogels was observed at low temperatures and in short calcination times by HT-XRD measurements $\left(150{ }^{\circ} \mathrm{C}, 1.5 \mathrm{~h}\right)$. However the resulting material was nonporous. ${ }^{21}$ Since a goal of our research is to synthesize new heterogeneous catalysts, we need to prepare thermally stable silicophosphates with high surface areas and preferably large pores (mesopores) that make acid sites accessible to broad 
range of substrates. Recently we succeeded in obtaining mesoporous organosilicophosphates by introducing bridging acetoxysilanes. $^{22}$ These hybrid xerogels exhibit surface area up to $700 \mathrm{~m}^{2} \mathrm{~g}^{-1}$ and maximum pore size of $9.0 \mathrm{~nm}$.

Block copolymers act as templates in aprotic organic solvents and provide short range order in metal oxides with wormhole pore structure..$^{23-26}$ In contrast, examples of ordered phosphate preparation are scarce. Here we report a novel synthesis of mesoporous nanocrystalline silicon orthophosphate by the non-hydrolytic sol-gel condensation in the presence of block copolymer Pluronic P123 and subsequent calcination in air. Silicon tetraacetate, $\mathrm{Si}(\mathrm{OAc})_{4},\left(\mathrm{Ac}=\mathrm{CH}_{3} \mathrm{CO}\right)$ and tris(trimethylsilyl)phosphate, $\mathrm{OP}\left(\mathrm{OSiMe}_{3}\right)_{3},(\mathrm{TTP})$ are used as precursors. The condensation reaction provides a clear gel at ambient temperature in 1-2 hours. The high homogeneity of Si and $\mathrm{P}$ mixing on an atomic level is a key property of these xerogels, which makes them easy to reproducibly transform into the crystalline silicon orthophosphate under mild conditions $\left(4 \mathrm{~h}, 500{ }^{\circ} \mathrm{C}\right)$. Pluronic P123 acts in the synthesis as a porogen and after being burned out provides mesoporosity in calcined nanocrystalline silicon orthophosphate. The surface is covered with strongly acidic $\mathrm{P}-\mathrm{OH}$ groups. Heterogeneous catalytic activity was tested in methylstyrene dimerization. ${ }^{3-5}$

\section{Experimental}

General synthetic procedures and characterization methods are described in the ESI. $\dagger$

\section{Non-hydrolytic sol-gel reactions}

In a typical reaction (Scheme 1), TTP (4.864 g; $15.48 \mathrm{mmol})$ was added dropwise within few minutes to a stirred solution of $\mathrm{Si}(\mathrm{OAc})_{4}(3.431 \mathrm{~g} ; 12.98 \mathrm{mmol})$ in toluene $\left(50 \mathrm{~cm}^{3}\right)$ at $80{ }^{\circ} \mathrm{C}$ under nitrogen. The molar ratio of precursors was 5Si : 6P (to be the same as in silicon orthophosphate $\mathrm{Si}_{5} \mathrm{P}_{6} \mathrm{O}_{25}$ ). After the addition was complete, the reaction mixture was vigorously stirred for $30 \mathrm{~min}$ and then a solution of Pluronic P123 (1.750 g) in toluene $\left(5.25 \mathrm{~cm}^{3}\right)$ was added and the resulting solution was stirred for additional $30 \mathrm{~min}$. The condensation reaction provided a clear colorless gel in $1 \mathrm{~h}$. The gel was kept at $80^{\circ} \mathrm{C}$ for one week during which time syneresis occurred. The gel was then dried under vacuum for $2 \mathrm{~d}$ and $5.679 \mathrm{~g}$ of a white xerogel (SiP-P) was obtained which was subsequently calcined in ambient atmosphere at $500{ }^{\circ} \mathrm{C}$ for $4 \mathrm{~h}$ (SiP-P-500). The samples after calcination were cooled in dry air to exclude the hydrolysis of Si-O-P bonds. The silicophosphate sample without template (SiP) was synthesized for the sake of comparison in a similar manner without Pluronic P123.

The degree of condensation, DC (\%) (eqn (1)), estimated from gravimetric analyses (precise weighing of the yield of the product and of the mass of starting precursors), represents the relative difference between the maximum theoretical loss of $\mathrm{AcOSiMe}_{3}$ in comparison to what is experimentally observed. This difference also defines the number of acetoxy groups on silicon and trimethylsilyl ester groups on phosphorus that are left in the matrix. $n_{\text {total }}$ in eqn (1) means the total molar amount

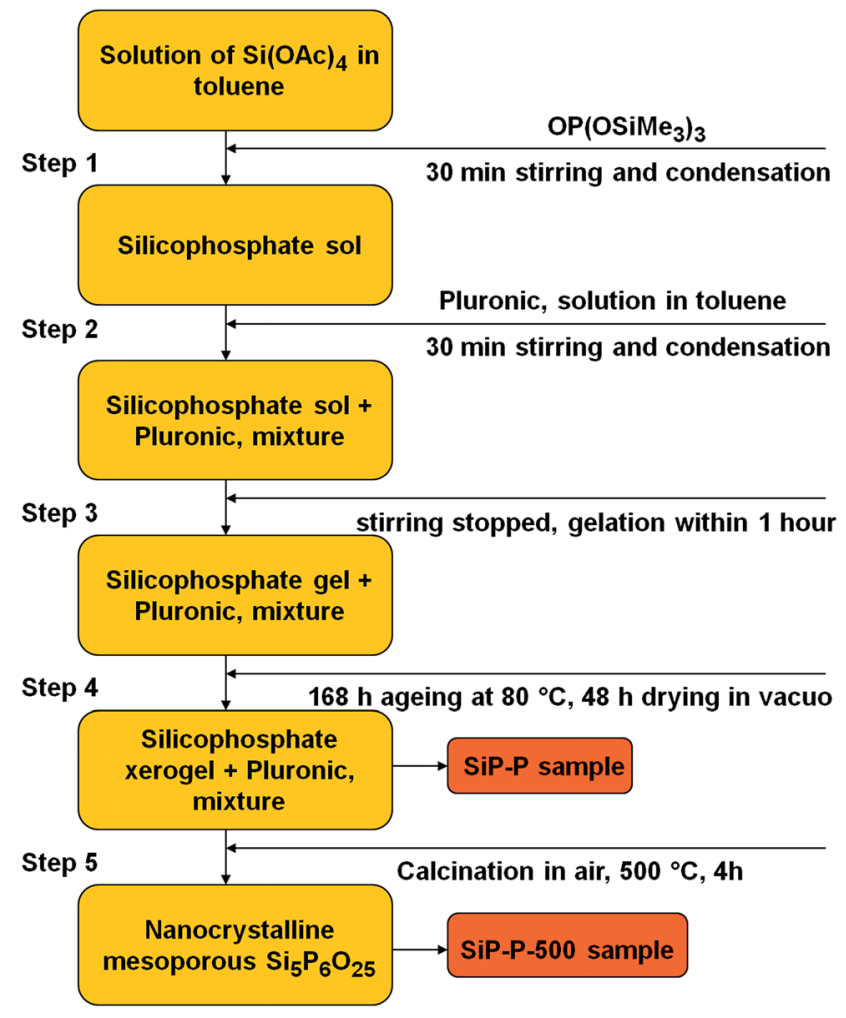

Scheme 1 Synthetic procedure for the preparation of mesoporous silicophosphates.

of organic groups in the reaction mixture and $n_{\text {residual }}$ is a molar amount of residual organic groups in the xerogel computed from difference of theoretical and experimental yield. The theoretical DC of $100 \%$ would correspond to product formula of $\mathrm{Si}_{5} \mathrm{P}_{6} \mathrm{O}_{24}(\mathrm{OAc})_{2}$ (eqn (2)). However the condensation reactions were never quantitative, therefore DC was used for calculating the theoretical mass loss, phosphorus and silicon content (w(P)\%, w(Si)\%).

$$
\mathrm{DC}=\left(n_{\text {total }}-n_{\text {residual }}\right) / n_{\text {total }}
$$

\section{Characterization and analyses}

SiP-P xerogel. TG/DSC (air, $5 \mathrm{~K} \mathrm{~min}^{-1}$ ): weight loss at $1000{ }^{\circ} \mathrm{C}: 57.6 \%$ (theor $57.2 \%$ ).

$\mathrm{IR}\left(\mathrm{KBr}, \mathrm{cm}^{-1}\right) \nu: 498 \mathrm{~m}, 652 \mathrm{w}\left(\nu \mathrm{SiC}_{3}\right), 762 \mathrm{w}\left(\rho_{\mathrm{s}} \mathrm{SiCH}_{3}\right), 853$ $\mathrm{m}\left(\rho_{\mathrm{as}} \mathrm{SiCH}_{3}\right), 1021 \mathrm{vw}\left(\rho \mathrm{CH}_{3}\right), 1050 \mathrm{sh}(\nu \mathrm{Si}-\mathrm{O}-\mathrm{P}), 1115$ vs $(\nu \mathrm{P}-$ $\mathrm{O}-\mathrm{Si}+\delta \mathrm{C}-\mathrm{O}-\mathrm{C}$ Pluronic $), 1258 \mathrm{~s}\left(\delta_{\mathrm{s}} \mathrm{SiCH}_{3}\right), 1300 \mathrm{sh}(\nu \mathrm{P}=\mathrm{O})$, $1377 \mathrm{w}\left(\delta_{\mathrm{s}} \mathrm{CH}_{3}\right), 1460 \mathrm{w}\left(\delta_{\mathrm{as}} \mathrm{CH}_{3}\right), 1542 \mathrm{~m}\left(\nu_{\mathrm{s}}\right.$ COO bidentate), $1707 \mathrm{vw}\left(\nu_{\mathrm{as}} \mathrm{COO}\right), 1766 \mathrm{~m}$ ( $\nu_{\text {as }} \mathrm{COO}$ monodentate), $2870 \mathrm{~m}\left(\nu_{\mathrm{s}}\right.$ $\left.\mathrm{CH}_{2}\right) 2907 \mathrm{vw}\left(\nu_{\mathrm{s}} \mathrm{CH}_{3}\right), 2934 \mathrm{~m}\left(\nu_{\text {as }} \mathrm{CH}_{2}\right), 2969 \mathrm{w}\left(\nu_{\text {as }} \mathrm{CH}_{3}\right)$.

${ }^{13} \mathrm{C}$ CPMAS NMR (ppm) $\delta:-0.5\left(\mathrm{POSiCH}_{3}\right), 16.0\left(\mathrm{CH}_{3} \mathrm{COO}\right.$ bident $+\mathrm{O}-\mathrm{CH}\left(\mathrm{CH}_{3}\right) \mathrm{CH}_{2}-$ Pluronic), 21.2 ( $\mathrm{CH}_{3} \mathrm{COO}$ unident), $69.8\left(\mathrm{O}-\mathrm{CH}_{2} \mathrm{CH}_{2}-\right.$ Pluronic), $72.6\left(\mathrm{O}-\mathrm{CH}\left(\mathrm{CH}_{3}\right) \mathrm{CH}_{2}-\right.$ Pluronic), 74.4 (O- $\mathrm{CH}\left(\mathrm{CH}_{3}\right) \mathrm{CH}_{2}-$ Pluronic), 165.8 ( $\mathrm{CH}_{3} \mathrm{COO}$ unident), $190.1\left(\mathrm{CH}_{3} \mathrm{COO}\right.$ bident$)$.

${ }^{29} \mathrm{Si}$ CPMAS NMR (ppm) $\delta: 25.0\left(\mathrm{POSiMe}_{3}\right),-108\left(\mathrm{SiO}_{4}\right),-196$ $\left(\mathrm{SiO}_{6}\right),-216\left(\mathrm{SiO}_{6}\right)$.

${ }^{31} \mathrm{P}$ MAS NMR $(\mathrm{ppm}) \delta:-41\left(\mathrm{P}(\mathrm{OSi})_{4}\right),-31\left(\mathrm{O}=\mathrm{P}(\mathrm{OSi})_{3}\right)$. 
SiP-P-500 xerogel. TG/DSC (air, $5 \mathrm{~K} \mathrm{~min}^{-1}$ ): weight loss at $1000{ }^{\circ} \mathrm{C}: 3.4 \%$.

IR $\left(\mathrm{KBr}, \mathrm{cm}^{-1}\right) \nu: 409 \mathrm{w}, 476 \mathrm{~m}, 498 \mathrm{w}, 553 \mathrm{~m}, 643 \mathrm{w}, 723 \mathrm{w}$, $807 \mathrm{w}, 1030 \mathrm{vs}, 1110 \mathrm{vs}, 1162 \mathrm{vs}, 1611 \mathrm{w}(\delta \mathrm{OH}), 1735 \mathrm{w}, 3449 \mathrm{w}$ $(\nu \mathrm{OH})$.

${ }^{29} \mathrm{Si}$ CPMAS NMR (ppm) $\delta:-104\left(\mathrm{SiO}_{4}\right),-119\left(\mathrm{SiO}_{4}\right),-213$ $\left(\mathrm{SiO}_{6}\right),-217\left(\mathrm{SiO}_{6}\right)$.

${ }^{31} \mathrm{P}$ MAS NMR $(\mathrm{ppm}) \delta:-44.7\left(\mathrm{P}(\mathrm{OSi})_{4}\right),-20.7\left(\mathrm{P}(\mathrm{OSi})_{2}(\mathrm{OH})_{2}\right)$. ICP-OES (\%): calcd Si 19.3, P 25.6. Exp. Si 19.2, P 24.3.

The organic product of the condensation reactions - trimethylsilylacetate, AcOSiMe $\mathrm{Al}_{3}$ - was identified by a combined GCMS technique with signals at $m / z 45 / 61 / 75 / 117$.

\section{a-Methylstyrene dimerization}

A suspension of SiP-P-500 (5 wt\%) in dry $\alpha$-methylstyrene $(2.0 \mathrm{~g})$ was prepared and the mixture heated to $90{ }^{\circ} \mathrm{C}$ for $6 \mathrm{~h}^{6}{ }^{6}$ The silicophosphate catalyst was then filtered off and, after dilution with toluene $(1: 20 \mathrm{vol})$, the product mixture was analyzed by GC-MS. The results were estimated on the basis of relative ratios of integrals of peaks in chromatograms, assuming that the different $\alpha$-methylstyrene dimers (Scheme $\mathrm{S} 1 \dagger$ ) will provide similar ion currents. The catalyst reusability was tested after separating it from the reaction mixture by centrifugation, washing three times with toluene $\left(10 \mathrm{~cm}^{3}\right)$, and drying in flowing nitrogen at room temperature. The dried catalyst was used again for the next $\alpha$-methylstyrene dimerization.

\section{Results and discussion}

Silicophosphate xerogels (SiP-P samples) were synthesized by the ester elimination route from silicon acetate and TTP (eqn (2)) in toluene as reported previously. ${ }^{21}$ The synthetic protocol was modified only in two parameters: (i) the $\mathrm{Si}: \mathrm{P}$ ratio was set to $5: 6$ to correspond to silicon orthophosphate $\mathrm{Si}_{5} \mathrm{P}_{6} \mathrm{O}_{25}$ and (ii) a templating agent Pluronic $\mathrm{P} 123$ was added into the reaction mixture after $30 \mathrm{~min}$ of condensation (Scheme 1). Gelation was achieved in the presence of Pluronic P123 and the expected condensation byproduct $\mathrm{AcOSiMe}_{3}$ (eqn (2)) was observed by GC-MS analysis of the reaction volatiles.

A very small amount of acetic acid was observed in volatiles. It was probably formed by the reaction of terminal hydroxyl groups of templating agent with silicon tetraacetate (initial $\mathrm{OH}$ : OAc ratio in starting materials was approximately $1: 100)$.

Ester elimination reactions generally proceed to condensation degrees (DC) of 78.7-84.7\% (eqn (3) represents DC = $84.7 \%$ ) which is comparable to silicophosphate xerogels without Pluronic P123 (SiP samples). ${ }^{21}$ Incomplete condensation resulted in the presence of unreacted organic groups (eqn (3), and discussion of IR and MAS NMR spectra below) which, upon calcination led to thermogravimetric mass losses of 57.6$60.5 \%$ at $1000{ }^{\circ} \mathrm{C}$ (Fig. 1). These mass losses are in good agreement with theoretical values computed from DC (see Experimental) and higher than observed in template-free SiP samples (29.5-40.4\%), the difference being the combustion of the Pluronic templating agent (Fig. 1).

$$
\begin{aligned}
& 5 \mathrm{Si}(\mathrm{OAc})_{4}+6 \mathrm{OP}\left(\mathrm{OSiMe}_{3}\right)_{3} \rightarrow \\
& \qquad \mathrm{Si}_{5} \mathrm{P}_{6} \mathrm{O}_{24}(\mathrm{OAc})_{2}+18 \mathrm{AcOSiMe}_{3}
\end{aligned}
$$

$$
\begin{aligned}
& 5 \mathrm{Si}(\mathrm{OAc})_{4}+ \text { 6OP }\left(\mathrm{OSiMe}_{3}\right)_{3} \rightarrow \\
& \mathrm{Si}_{5} \mathrm{P}_{6} \mathrm{O}_{21.3}(\mathrm{OAc})_{2+2.7}\left(\mathrm{OSiMe}_{3}\right)_{2.7}+15.3 \mathrm{AcOSiMe}_{3}
\end{aligned}
$$

As already presented above, the Pluronic template did not hinder the condensation reaction and the same conclusion was made for the structure of the xerogels after the examination of IR and MAS NMR spectra. The infrared spectra of SiP and SiP-P samples (Fig. 2) exhibit strong bands at $1100 \mathrm{~cm}^{-1}$, which is typical for homogeneous silicophosphate glasses ${ }^{27,28}$ as well as for parent homogeneous silicophosphate xerogels $(\mathrm{SiP})^{\mathbf{2 1}}$ and serves as a benchmark for the Si-O-P bonds. ${ }^{12,13,17,29,30}$ The presence of residual trimethylsilyl and acetoxy groups was gleaned from strong bands located at 762, 853, and $1258 \mathrm{~cm}^{-1}$ $\left(\mathrm{Me}_{3} \mathrm{SiO}\right)$ and 1021, 1542, 1707, and $1766 \mathrm{~cm}^{-1}$ (AcO) in both samples as well. The only significant differences between the IR spectra of SiP-P and SiP samples (Fig. 2) are absorption bands located at 1115, 1348, 2870, and $2934 \mathrm{~cm}^{-1}$ which we assign to $\nu(\mathrm{C}-\mathrm{O}-\mathrm{C}), \nu(\mathrm{C}-\mathrm{C}), \nu_{\mathrm{s}}\left(\mathrm{CH}_{2}\right)$ and $\nu_{\text {as }}\left(\mathrm{CH}_{2}\right)$, respectively, from the templating agent Pluronic P123. ${ }^{31}$ To conclude, the IR spectra suggest that SiP-P sample is a mixture of silicophosphate xerogel with Pluronic. There are no hints of changes in the structure, destruction of the Si-O-P skeleton or lowering the homogeneity.

The conclusions drawn from the IR spectra were confirmed by MAS NMR spectroscopy. The ${ }^{29}$ Si CPMAS spectrum of SiP-P sample (Fig. $\mathrm{S} 1 \dagger$ ) consisted of four resonances at $25.8 \mathrm{ppm}$ (unreacted $\left.\mathrm{Me}_{3} \mathrm{SiO}\right),-108 \mathrm{ppm}\left(\mathrm{SiO}_{4}\right),-196 \mathrm{ppm}\left(\mathrm{SiO}_{6}\right.$, additional coordination of carboxyls of residual acetoxy groups), and $-216 \mathrm{ppm}$ ( $\mathrm{SiO}_{6}$, additional coordination of phosphoryl groups) which exactly matched the ones observed in our parent silicophosphate xerogels (SiP, Fig. S1 $)^{21}{ }^{21} \mathrm{P}$ MAS NMR spectrum (Fig. 3, bottom) displayed only one broad resonance with maximum at $-40 \mathrm{ppm}$ typical for $\mathrm{P}(\mathrm{OSi})_{4}$ moieties $^{\mathbf{2 1 , 2 2}}$ with a shoulder at $-31 \mathrm{ppm}$ assigned to $\mathrm{O}=\mathrm{P}(\mathrm{OSi})_{3}$ groups. $^{32-34} \mathrm{New}$

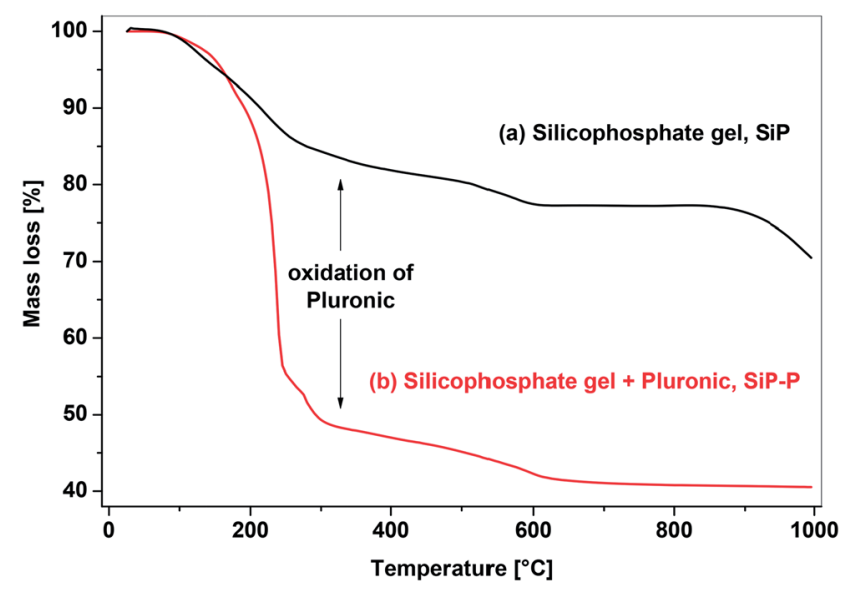

Fig. $1 \mathrm{TG}$ analyses of SiP and SiP-P samples, heating rate $5{ }^{\circ} \mathrm{C} \mathrm{min}^{-1}$, to $1000^{\circ} \mathrm{C}$. 


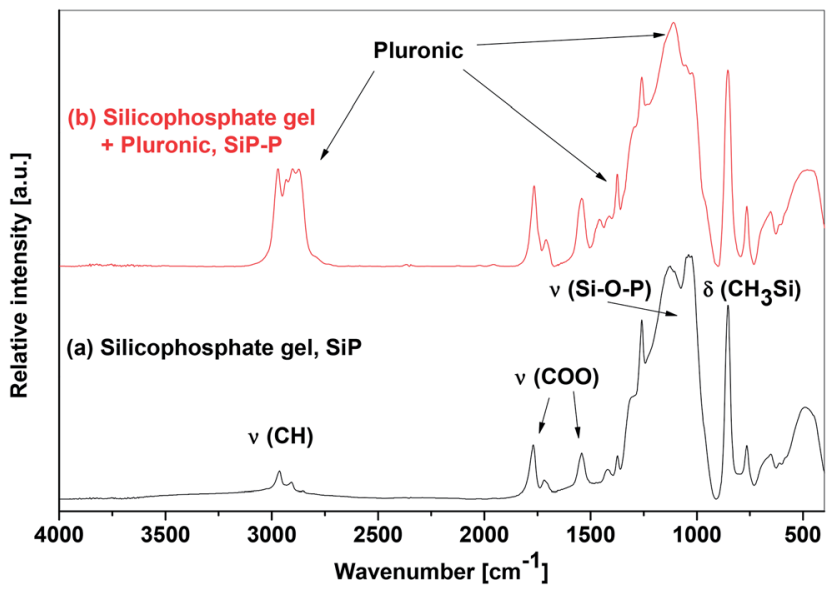

Fig. 2 IR spectra of SiP and SiP-P xerogels in $\mathrm{KBr}$ pellets.

signals (in contrast to SiP samples) were observed only in ${ }^{13} \mathrm{C}$ CPMAS NMR spectra (Fig. S2 $\dagger$ ) - in addition to the signals of $\mathrm{Me}_{3} \mathrm{SiOP}$ groups ( $-0.5 \mathrm{ppm}$ ), unidentate $\mathrm{AcO}$ groups (21.2 and $165.8 \mathrm{ppm}$ ) and bidentate AcO groups (16.0 and $190.1 \mathrm{ppm}$ ), the signals of polyethylene oxide-polypropylene oxide copolymer were present at $16.0 \mathrm{ppm}$ (methyl group, $\mathrm{O}-\mathrm{CH}\left(\mathrm{CH}_{3}\right) \mathrm{CH}_{2}$ ), $69.8 \mathrm{ppm}\left(\mathrm{O}-\mathrm{CH}_{2} \mathrm{CH}_{2}\right), 72.6 \mathrm{ppm}\left(\mathrm{O}-\mathrm{CH}\left(\mathrm{CH}_{3}\right) \mathrm{CH}_{2}\right)$ and 74.4 ppm $\left(\mathrm{O}-\mathrm{CH}\left(\mathrm{CH}_{3}\right) \mathrm{CH}_{2}\right) \cdot{ }^{35,36}$ The MAS NMR spectra revealed, that the important structural units, such as $\mathrm{SiO}_{6}\left(\right.$ carboxyl), $\mathrm{SiO}_{6}$ (phosphoryl), $\mathrm{P}(\mathrm{OSi})_{4}, \mathrm{Me}_{3} \mathrm{SiOP}$, uni- and bidentate acetates of the parent silicophosphate were retained within the templated SiP-P samples. No influence of Pluronic on either condensation or structure was observed and thus we started to follow the thermal transformations of SiP-P xerogels.

As reported previously, silicon orthophosphate $\mathrm{Si}_{5} \mathrm{P}_{6} \mathrm{O}_{25}$ starts to crystallize from the SiP xerogels already at $150{ }^{\circ} \mathrm{C},{ }^{21}$ however there are several other processes that occur during the calcination of the SiP-P samples - oxidation of Pluronic, oxidation of residual trimethylsilyl groups and hydrolysis of resulting silicon phosphate in moist air. We used the temperatures from 500 to $700{ }^{\circ} \mathrm{C}$ for the calcination of SiP-P samples as

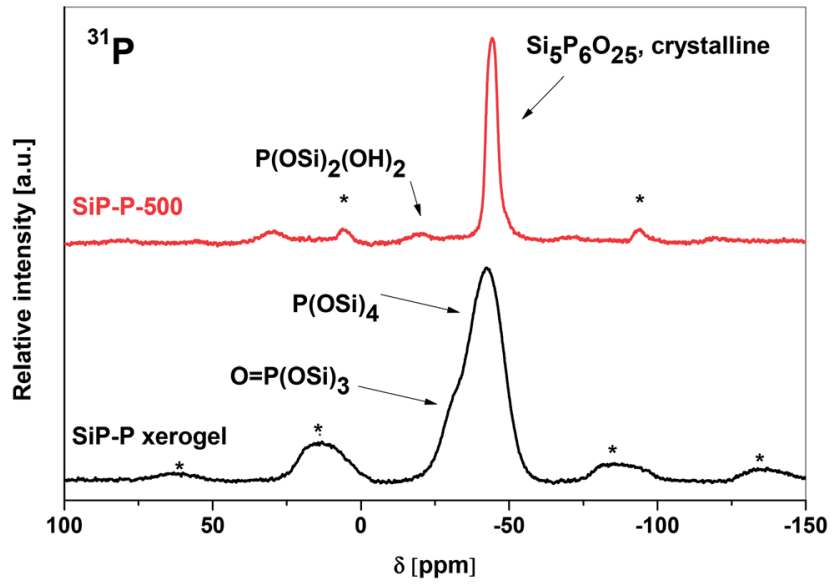

Fig. $3{ }^{31}$ P MAS NMR spectra of SiP-P xerogel (bottom) and SiP-P-500 sample (upper). Rotation rate $10 \mathrm{kHz}$ * marks spinning sidebands. at lower temperatures black color was formed. We tested the influence of moisture in the atmosphere during the calcination and found that trimethylsilyl groups are more easily eliminated as trimethylsilanol or hexamethyldisiloxane in ambient atmosphere, while the calcination in dry synthetic air leads mostly to their oxidation to $\mathrm{SiO}_{2}$, which is then present as an admixture in the samples (as revealed by ${ }^{29} \mathrm{Si}$ CPMAS and ICP-OES analysis of $\mathrm{Si}$ and P). Finally, the resulting silicon orthophosphate was found to partially hydrolyze during cooling in ambient atmosphere $\left({ }^{31} \mathrm{P}\right.$ MAS, XRD). Therefore we calcined the samples to $500{ }^{\circ} \mathrm{C}$ for $4 \mathrm{~h}$ (heating ramp $5{ }^{\circ} \mathrm{C} \mathrm{min}^{-1}$ ) in ambient atmosphere and then we let the samples cool down in dry atmosphere (SiP-P-500). Following this procedure we reproducibly obtained white crystalline samples, with only a small amount of $\mathrm{SiO}_{2}(5-8 \%)$, and silicon orthophosphate was not hydrolyzed (Scheme 1, step 5).

The XRD analysis of the calcined samples (SiP-P-500) unambiguously proved that the resulting white powder can be described as silicon orthophosphate, $\mathrm{Si}_{5} \mathrm{P}_{6} \mathrm{O}_{25}$ (PDF 40-457). No evidence of any other crystalline phases was observed and the content of amorphous phase was estimated to be $18 \mathrm{wt} \%$. The composition of amorphous phase is discussed below. The Bragg peaks for $\mathrm{Si}_{5} \mathrm{P}_{6} \mathrm{O}_{25}$ are broad (Fig. 4) suggesting these materials are made up of small crystallites, which had an average size of $16 \mathrm{~nm}$ based on the Debye-Scherrer equation. It is notable that the formation of crystalline phase is relatively fast in comparison with other procedures, where the crystallization of $\mathrm{Si}_{5} \mathrm{P}_{6} \mathrm{O}_{25}$ has only been observed after melting silica gel and phosphoric acid for several days. ${ }^{7,12,13,19}$ This effect is caused by homogeneous $\mathrm{Si} / \mathrm{P}$ mixing at the molecular level, which is the major advantage of our non-hydrolytic sol-gel technique (Scheme 1, eqn (2)).

The crystal structure of silicon orthophosphate consists of three distinct Si sites - two octahedral and one tetrahedral ${ }^{14,16}$ consistent with what is observed in the ${ }^{29} \mathrm{Si}$ CPMAS NMR spectrum (Fig. S1, $\dagger$ resonances at $-119,-213$, and $-217 \mathrm{ppm}$ ). Chemical shifts are in the good agreement with the published data. ${ }^{33,34}$ These results together with the XRD analysis lead to

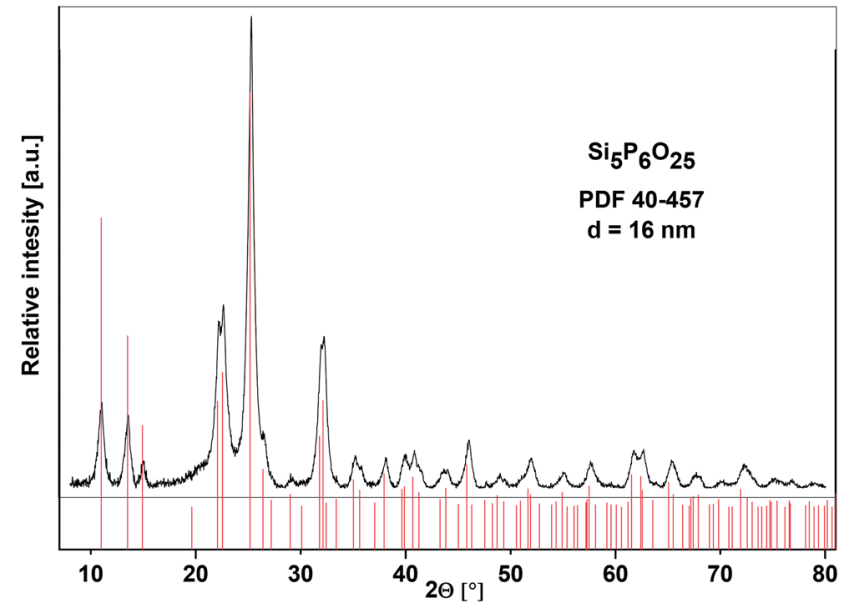

Fig. 4 XRD diffractogram of SiP-P-500 sample and corresponding PDF card of silicon orthophosphate. 
the conclusion that $\mathrm{SiP}-\mathrm{P}-500$ consists predominately of $\mathrm{Si}_{5} \mathrm{P}_{6} \mathrm{O}_{25}$. There is an additional signal at $-104 \mathrm{ppm}$ observed in the ${ }^{29} \mathrm{Si}$ CPMAS NMR spectrum (Fig. S1 $\dagger$ ). This could be ascribed to amorphous silica ${ }^{33}$ which is formed by partial oxidation of the $\mathrm{Me}_{3} \mathrm{SiO}$ groups during the calcination of the SiP-P samples. As already discussed, the silica content is lower if the calcination is performed in ambient (moist) atmosphere instead of dry air.

There is only one type of phosphate group present in the structure of silicon orthophosphate represented by a resonance at $-44.7 \mathrm{ppm}$ in the ${ }^{31} \mathrm{P}$ MAS NMR spectrum (Fig. 3, upper), again in a very good agreement with published data. ${ }^{33,34}$ This major signal is accompanied by a peak of very low intensity at $-20.7 \mathrm{ppm}$, which could be assigned to $\mathrm{P}(\mathrm{OSi})_{2}(\mathrm{OH})_{2}$ or $\mathrm{O}=\mathrm{P}(\mathrm{OH})(\mathrm{OSi})_{2}$ according to the recent literature ${ }^{37,38}$ and arises probably from the surface phosphate groups which are terminated with hydroxyl groups. The formation of Brønsted acidic $\mathrm{P}-\mathrm{OH}$ groups on the surface was independently confirmed by a peak at $8.5 \mathrm{ppm}$ in the ${ }^{1} \mathrm{H}$ MAS NMR spectrum of SiP-P-500.

The IR spectra of SiP-P-500 were recorded in order to establish the nature of structural units present in the calcined samples. A typical spectrum is shown in Fig. 5a and displays absorption bands of valence vibrations (900-1350 $\mathrm{cm}^{-1}$ ) and deformation vibrations $\left(400-850 \mathrm{~cm}^{-1}\right)$ of $\mathrm{Si}-\mathrm{O}-\mathrm{P}$ and $\mathrm{Si}-\mathrm{O}-\mathrm{Si}$ bonds. ${ }^{9,39}$ The recorded spectra agree well with the data reported by Malshikov for crystalline silicon orthophosphate, $\mathrm{Si}_{5} \mathrm{P}_{6} \mathrm{O}_{25}{ }^{9}$ There is also a broad band at $3400 \mathrm{~cm}^{-1}$ of $\mathrm{OH}$ valence vibrations which corroborates the presence of surface hydroxyl groups. The IR spectra of pyridine-treated sample (Fig. 5b) displayed in additional absorption bands of pyridinium cation ${ }^{40,41}$ at 1490,1542 , and $1638 \mathrm{~cm}^{-1}$ and confirmed Brønsted acidity of silicon orthophosphates.

Useful information about the amount of silicon dioxide admixture was gained by the ICP-OES analysis of Si and $\mathrm{P}$ contents in mineralized samples. The nominal Si : P ratio $5: 6$ changed to the benefit of silicon. It was not caused by the loss of phosphorus at higher temperatures, ${ }^{21}$ which is frequently observed at the silicophosphate products of hydrolytic sol-gel

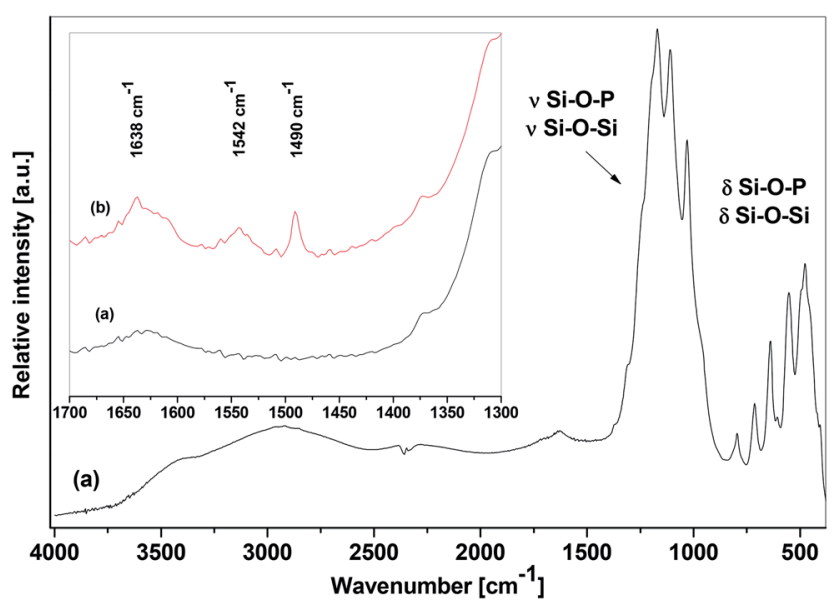

Fig. 5 IR spectra of SiP-P-500 sample stored in dry atmosphere (a) and exposed to pyridine at its autogeneous pressure (b). syntheses due to the low cross-linking between $\mathrm{Si}$ and $\mathrm{P},{ }^{\mathbf{1 1 - 1 3 , 1 9}}$ but it was caused by the partial oxidation of trimethylsilyl groups to silica. The $\mathrm{Si}: \mathrm{P}$ ratio in the SiP-P-500 samples was in the range from $5.2: 6$ to $5.5: 6$. In other words, silica formed 5$8 \mathrm{wt} \%$ of resulting samples thus being only a minor phase. This value is in broad agreement with quantity of amorphous phase (18 wt\%) determined by XRD. The amorphous phase may consist not only of silicon dioxide but also of some small part of non-crystalline silicophosphate.

The degree of ordering was followed by the SAXS measurement. The uncalcined samples (SiP-P) showed one scattering maximum indicating a short range order similar to materials prepared by $\mathrm{Kriesel}^{24}$ in toluene (Fig. S3†). This peak was lost during the calcination to $500{ }^{\circ} \mathrm{C}$ (SiP-P-500), probably due to crystallization of the silicon orthophosphate phase (Fig. S3†). Therefore we focused on alternative methods of low temperature removal of Pluronic P123 template, such as ozonolysis, $\mathrm{BBr}_{3}$ cleavage, and oxidation by dry oxygen at $60{ }^{\circ} \mathrm{C}$ combined with extraction into $\mathrm{CH}_{2} \mathrm{Cl}_{2}$. With these procedures we were able to remove at most $15.8 \%$ of the template according to TGA, while the ordered mesostructure was maintained.

The nitrogen adsorption-desorption isotherm of SiP-P-500 with its DFT pore size distribution is shown in Fig. 6. According to IUPAC nomenclature the obtained isotherm is type IV, characteristic of mesoporous materials. Since the steep hysteresis loop is observed in the $p / p_{0}$ region from 0.8 to 1.0 , it could be suggested that the samples contain high degree of textural porosity. ${ }^{\mathbf{2 4 4 2}}$ This is in agreement with SAXS measurements of SiP-P-500 sample. The surface areas determined by the BET method ranged from 92 to $128 \mathrm{~m}^{2} \mathrm{~g}^{-1}$ for samples from different batches, total pore volumes (at $p / p_{0}=0.976$ ) reached from 0.503 to $0.595 \mathrm{~cm}^{3} \mathrm{~g}^{-1}$ and average pore diameters were in the range from 18 to $22 \mathrm{~nm}$. The DFT pore size distribution was relatively narrow with pore diameters ranging from 10 to $45 \mathrm{~nm}$. Materials with textural porosity usually show wider pore size ranges so the SiP-P-500 sample probably contains certain fraction of structure confined porosity. ${ }^{24}$ According to the $t$-plot analyses there were no micropores present in the samples.

These results signal a significant improvement of our materials in the context of heterogeneous catalysis applications. While the parent SiP xerogels were microporous and their heating resulted in nonporous silicon orthophosphate, these new SiP-P-500 samples are thermally stable, possess reasonable high specific surface areas and are mesoporous with relatively narrow pore size distributions. To our knowledge, this is the first example of the synthesis of crystalline and mesoporous silicon orthophosphate.

The SEM and TEM images of calcined silicophosphates prepared with the Pluronic template are shown in Fig. 7. The SEM image shows the vermicular nature of the SiP-P-500 sample where the sponge-like porous structure can be seen and thus corroborates the results of $\mathrm{N}_{2}$ adsorption-desorption experiments. In contrast the SEM image of calcined SiP sample (Fig. S4 $\dagger$ ) shows agglomerated particles. The agglomeration is probably reason for the low surface area of the sample $\left(<10 \mathrm{~m}^{2}\right.$ $\left.\mathrm{g}^{-1}\right)$. The TEM image shows the primary particles of SiP-P-500 


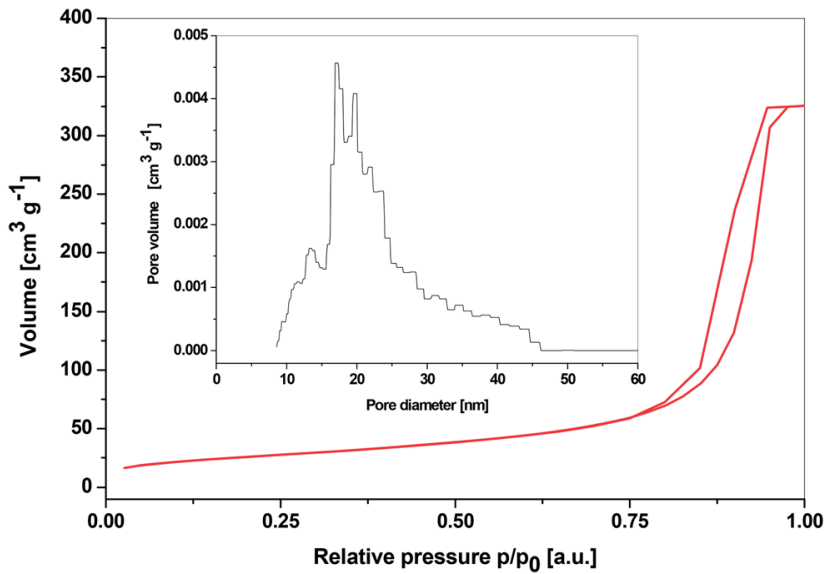

Fig. $6 \mathrm{~N}_{2}$ adsorption-desorption isotherms of SiP-P-500 sample and its DFT pore size distribution (inset, DFT Kernel used: $\mathrm{N}_{2}$ at $77 \mathrm{~K}$ on silica, cylindrical pore, NSDFT equilibrium model).

sample. Their sizes are consistent with the results of XRD analyses of crystallite size $(16 \mathrm{~nm})$.

Characteristics of SiP-P-500 sample (mesoporosity, Brønsted acidity) suggest that these materials could serve as solid phosphoric acid catalysts. Therefore we performed catalytic tests on $\alpha$-methylstyrene dimerization, which is catalyzed by acidic protons. ${ }^{6}$ Various homogeneous and heterogeneous Brønsted acids were tested recently and the best results among heterogeneous catalysts were achieved with phosphoric acid impregnated on silica (conversion $97.5 \%$, selectivity $94.7 \%, 2-5 \mathrm{wt} \%$ of catalyst in neat methylstyrene, $\left.6 \mathrm{~h}, 90{ }^{\circ} \mathrm{C}\right) .{ }^{6}$ We used the same conditions for this reaction and the SiP-P-500 sample with the surface $\mathrm{P}-\mathrm{OH}$ groups performed the catalytic reaction with up to $99 \%$ conversion of $\alpha$-methylstyrene and $99 \%$ selectivity toward cyclic dimer I (Scheme S1, $\uparrow$ GC-MS). The reused catalyst maintained very high conversion of $99 \%$ in the second catalytic run. Meantime the selectivity only slightly decreased to $98 \%$. Heterogeneous nature of catalytic action is supported by the absence of phosphorus in the reaction solution (ICP-OES). We compared the catalytic action of porous sample SiP-P-500 with nonporous crystalline sample prepared without a template (SiP500 ) and found out that the latter reached almost complete conversion of methylstyrene after $6 \mathrm{~h}$ at $90{ }^{\circ} \mathrm{C}$ as well. Therefore
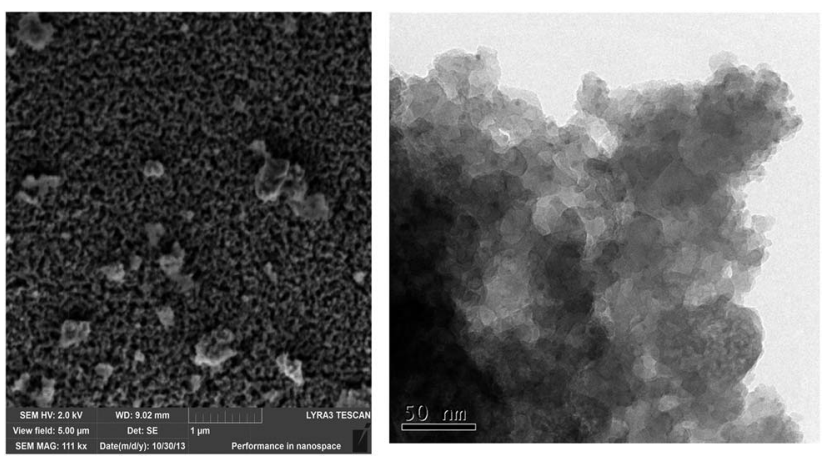

Fig. 7 SEM (left) and TEM (right) image of SiP-P-500 sample. we decreased the reaction time and temperature to $5 \mathrm{~min}$ and $50{ }^{\circ} \mathrm{C}$. While conversion remained high for SiP-P-500 (98\%), it dropped to $89 \%$ for SiP-500. Selectivity changed for both catalysts to 47 and $45 \%$ of terminal dimer (II).

Our catalysts possess a large amount of phosphorus species dispersed homogeneously on the surface. Therefore we believe, that these mesoporous nanocrystalline silicon phosphates would show an increased stability in comparison with phosphoric acid impregnated on silica.

\section{Conclusions}

All the data in hand showed that our synthetic procedure relying on non-hydrolytic polycondensation between silicon tetraacetate, $\mathrm{Si}(\mathrm{OAc})_{4}$, and tris(trimethylsilyl)phosphate, $\mathrm{OP}\left(\mathrm{OSiMe}_{3}\right)_{3}$, in the presence of templating agent Pluronic P123 and subsequent short calcination resulted in the formation of nanocrystalline, mesoporous silicon orthophosphate, $\mathrm{Si}_{5} \mathrm{P}_{6} \mathrm{O}_{25}$, with surface areas up to $128 \mathrm{~m}^{2} \mathrm{~g}^{-1}$ and pore sizes around $20 \mathrm{~nm}$. The porosity is mainly of textural type. The short calcination time needed for the crystallization to silicon orthophosphate $\mathrm{Si}_{5} \mathrm{P}_{6} \mathrm{O}_{25}$ was achieved through the atomic homogeneity of silicophosphate xerogels with high content of $\mathrm{Si}-\mathrm{O}-\mathrm{P}$ bonds resulting from the non-hydrolytic condensation reaction. The nanocrystalline and mesoporous silicon orthophosphate was covered with surface $\mathrm{P}-\mathrm{OH}$ groups providing Brønsted acidity. These xerogels showed superior catalytic behavior in methylstyrene dimerization and are promising materials for potential heterogeneous catalysis applications.

\section{Acknowledgements}

Authors thank the project CEITEC - Central European Institute of Technology CZ.1.05/1.1.00/02.0068, Structural Analysis Laboratory of CEITEC, and KONTAKT II LH11028 for the financial assistance. J. P. thanks to the Fulbright Foundation for a scholarship. A. S. thanks to the Brno City Municipality for Brno PhD Talent Scholarship. Authors thank Dr K. Novotny and L Simonikova for ICP-OES analyses, Dr M. Klementova for TEM analyses and T. Samoril for SEM images.

\section{References}

1 M. Mika, M. Paidar, B. Klapste, M. Masinova, K. Bouzek and J. Vondrak, J. Phys. Chem. Solids, 2007, 68, 775-779.

2 A. Matsuda, T. Kanzaki, K. Tadanaga, M. Tatsumisago and T. Minami, Solid State Ionics, 2002, 154-155, 687-692.

3 C. M. Fougret and W. F. Hölderich, Appl. Catal., A, 2001, 207, 295-301.

4 F. Cavani, G. Girotti and G. Terzoni, Appl. Catal., A, 1993, 97, 177-196.

5 T. R. Krawietz, P. Lin, K. E. Lotterhos, P. D. Torres, D. H. Barich, A. Clearfield and J. F. Haw, J. Am. Chem. Soc., 1998, 120, 8502-8511.

6 G. N. Kirichenko, N. G. Grigoreva, V. I. Glazunova and U. M. Dzhemilev, Petroleum Chemistry, 2009, 49, 306-310. 
7 F. Liebau, G. Bissert and N. Köppen, Z. Anorg. Allg. Chem., 1968, 359, 113-134.

8 H. Makart, Helv. Chim. Acta, 1967, 50, 399-405.

9 A. E. Malshikov, Russ. J. Inorg. Chem., 1987, 32, 1383-1385.

10 W. A. Gambling, D. N. Payne, C. R. Hammond and S. R. Norman, Proc. Inst. Electr. Eng., 1976, 123, 570.

11 F. Tian, L. Pan, X. Wu and F. Wu, J. Non-Cryst. Solids, 1988, 104, 129-134.

12 Y. S. Kim and R. E. Tressler, J. Mater. Sci., 1994, 29, 25312535.

13 A. Aronne, M. Turco, G. Bagnasco, P. Pernice, M. Di Serio, N. J. Clayden, E. Marenna and E. Fanelli, Chem. Mater., 2005, 17, 2081-2090.

14 D. M. Poojary, R. B. Borade and A. Clearfield, Inorg. Chim. Acta, 1993, 208, 23-29.

15 D. M. Poojary, R. B. Borade, F. L. Campbell III and A. Clearfield, J. Solid State Chem., 1994, 112, 106-112.

16 H. Mayer, Monatsh. Chem., 1974, 105, 46-54.

17 P. Massiot, M. A. Centeno, I. Carrizosa and J. A. Odriozola, J. Non-Cryst. Solids, 2001, 292, 158-166.

18 C. Fernández-Lorenzo, L. Esquivias, P. Barboux, J. Maquet and F. Taulelle, J. Non-Cryst. Solids, 1994, 176, 189-199.

19 S.-P. Szu, L. C. Klein and M. Greenblatt, J. Non-Cryst. Solids, 1992, 143, 21-30.

20 A. Matsuda, T. Kanzaki, Y. Kotani, M. Tatsumisago and T. Minami, Solid State Ionics, 2001, 139, 113-119.

21 A. Styskalik, D. Skoda, Z. Moravec, J. G. Abbott, C. E. Barnes and J. Pinkas, Microporous Mesoporous Mater., 2014, 197, 204-212.

22 A. Styskalik, D. Skoda, Z. Moravec, M. Babiak, C. E. Barnes and J. Pinkas, J. Mater. Chem. A, 2015, 3, 7477-7487.

23 P. T. Tanev and T. J. Pinnavaia, Chem. Mater., 1996, 8, 20682079.

24 J. W. Kriesel, M. S. Sander and T. D. Tilley, Chem. Mater., 2001, 13, 3554-3563.

25 P. Yang, D. Zhao, D. I. Margolese, B. F. Chmelka and G. D. Stucky, Chem. Mater., 1999, 11, 2813-2826.
26 D. Skoda, A. Styskalik, Z. Moravec, P. Bezdicka and J. Pinkas, J. Mater. Sci., 2015, 50, 3371-3382.

27 J. Wong, J. Non-Cryst. Solids, 1976, 20, 83-100.

28 N. Shibata, M. Horigudhi and T. Edahiro, J. Non-Cryst. Solids, 1981, 45, 115-126.

29 H. Niida, M. Takahashi, T. Uchino and T. Yoko, J. Mater. Res., 2003, 18, 1-3.

30 Z. Cao, B. I. Lee, W. D. Samuels, L.-Q. Wang and G. J. Exarhos, J. Mater. Res., 1998, 13, 1553-1559.

31 F. S. Freitas, J. N. de Freitas, B. I. Ito, M.-A. D. Paoli and A. F. Nogueira, ACS Appl. Mater. Interfaces, 2009, 1, 28702877.

32 S. Jähnigen, E. Brendler, U. Böhme and E. Kroke, Chem. Commun., 2012, 48, 7675.

33 C. Coelho, T. Azais, L. Bonhomme-Coury, J. Maquet, D. Massiot and C. Bonhomme, J. Magn. Reson., 2006, 179, 114-119.

34 C. Lejeune, C. Coelho, L. Bonhomme-Coury, T. Azaïs, J. Maquet and C. Bonhomme, Solid State Nucl. Magn. Reson., 2005, 27, 242-246.

35 H. M. Kao, C. L. Chen and S. W. Chiao, J. Chin. Chem. Soc., 2005, 52, 693-699.

36 S. Choe, M. J. Kim, H. C. Kim, T. Lim, K. J. Park, K. H. Kim, S. H. Ahn, A. Lee, S.-K. Kim and J. J. Kim, J. Electroanal. Chem., 2014, 714-715, 85-91.

37 S. Jähnigen, E. Brendler, U. Böhme, G. Heide and E. Kroke, New J. Chem., 2014, 38, 744.

38 C. Coelho, T. Azais, C. Bonhomme, L. Bonhomme-Coury, C. Boissière, G. Laurent and D. Massiot, C. R. Chim., 2008, 11, 387-397.

39 B. Lelong, Ann. Chim., 1964, 9, 229-260.

40 M. Lefrancois and G. Malbois, J. Catal., 1971, 20, 350-358.

41 R. B. Borade and A. Clearfield, Appl. Catal., A, 1992, 80, 5977.

42 K. S. Sing, D. H. Everett, R. A. W. Haul, L. Moscou, R. A. Pierotti, J. Rouquerol and T. Siemieniewska, Pure Appl. Chem., 1985, 57, 603-619. 